\title{
Embracing a dialogue about cost and value in physiotherapy education
}

\author{
Jonathan Foo ${ }^{1}$ and Stephen Maloney ${ }^{1}$
}

1. Department of Physiotherapy, Monash University, Australia

Submitted: 20 March, 2018 | Accepted: 15 June, 2018 | DOI: 10.14426/art/474

\begin{abstract}
Physiotherapy education cannot occur without resources. A pragmatic approach to education design is required, with explicit consideration for the cost of our teaching and learning practices. In this editorial, we explore the concept of cost-conscious educational design in the context of physiotherapy education.
\end{abstract}

Keywords: cost, physiotherapy education, value

Copyright: This work is licensed under a Creative Commons Attribution 4.o International License.

\section{Practical implications: Key tips for cost-aware educational design}

1. Personnel costs

a. Design for economies of scale

b. Consider costs from the perspective of fixed and variable

2. Facility costs

a. Aim to minimise the volume of in-room time

b. Match educational needs with the lowest cost facility type

3. Equipment costs

a. Design for economies of scope

b. Cost is not always an indicator of educational value

4. Client input costs

a. Consider all relevant stakeholders

b. Look out for cost-shifting between stakeholders

\section{Introduction}

Resources for education are limited. Choices must - and will be made about their allocation. As educators, it is our responsibility to not only consider optimal learner outcomes, but also the cost of achieving these outcomes. Consideration of cost is necessary to ensure efficiency and sustainability of physiotherapy education practices (Maloney, 2017). Despite the importance of resource allocation, physiotherapy education appears to be occurring with little systematic thought on the economic costs involved. A quick PubMed search (conducted January 3, 2018) combining MeSH terms for physiotherapy education and cost analyses returns a paltry 9 articles, compared with 208 and 1199 for nursing and medicine respectively.

Issues of cost are ubiquitous - affecting the viability of existing programs, the introduction of new programs, and the uptake of educational innovations. The cost of education will play a key role in the future development of the global physiotherapy profession, particularly if we are

\section{Corresponding author}

Jonathan Foo (jon.foo@monash.edu)

ORCID: https://orcid.org/oooo-0003-4533-8307

Department of Physiotherapy, Monash University, Australia to attain the educational standards outlined by the World Confederation for Physical Therapy (World Confederation for Physical Therapy, 2015b).

For example, building capacity for independent autonomous practice, which is currently met by only $63 \%$ of countries (World Confederation for Physical Therapy, 2015a), requires additional training in analytical and research skills (Bithell, 2007), as well as further professional mentorship and clinical experience (McMeeken, Webb, Krause, Grant, \& Garnett, 2005) - all of which is likely to result in qualification inflation (i.e. increase from 3-year diploma to 4-year baccalaureate).

Improved management of educational resources will generate better learner outcomes (or a higher number of graduates) for the same cost, or the same learner outcomes for a lower cost (Maloney et al., 2015). Respectively, these features of improved management addresses the growing demand for physiotherapy services (Pretorius, Karunaratne, \& Fehring, 2015), and the heightening budget constraints on educational programs 
(Walsh, 2010). From this, it is clear that 'value' in education is dependent on two factors, the educational outputs, and the cost of resource inputs. In this editorial, we explore how purposeful educational design can be used to address the latter of these two elements - cost.

We explore the concept of costs, drawing on Levin's Ingredients Framework, a framework commonly used in the field of educational economics (Levin, McEwan, Belfield, Bowden, \& Shand, 2017). Levin proposes several key categories of costs to consider, including personnel, facilities, equipment and materials, and client inputs (McEwan, 2012).

\section{Personnel costs}

The largest recurring cost in a physiotherapy program is likely to be personnel costs (Finucane \& McCrorie, 2010). Personnel costs include direct teaching staff, administration, support services, and those related to clinical education. Curriculum designers may optimise personnel usage by considering economies of scale, and the associated concepts of fixed costs and variable costs. Fixed costs are educational costs that occur regardless of the number of students taught, whereas variable costs change based on the number of students.

Technology enhanced learning (e-learning) approaches provide useful examples of fixed and variable costs. They typically require large initial investments to develop (fixed cost), however once established, the program is often usable by a large number of dispersed learners and for multiple iterations (Cook, 2007) thereby lowering the per student variable cost. In their randomised controlled trial, Maloney et al. (2012) show that there is no difference between traditional face-to-face teaching and pre-recorded video teaching for physiotherapy practical skills when measured by Objective Structured Clinical Examination. Massive Open Online Courses (MOOCs), such as the one conducted by Harvey and colleagues teaching thousands of physiotherapists about spinal cord injuries, are an extreme example of the economies of scale principle (Harvey, Glinsky, Lowe, \& Lowe, 2014). Several other factors related to economies of scale are presented in Box 1 below.

\section{Box 1. Applying economies of scale in physiotherapy education}

\section{Look beyond physiotherapy}

Physiotherapy and occupational therapy content is sufficiently similar to allow for sharing of educational resources (Brown \& Jennifer, 1999) . Sharing of resources can lower both fixed and variable costs, and may be applied more broadly to the generic elements of physiotherapy education, including anatomy, physiology, biomechanics, and evidence based practice (Maloney, Moss, Keating, Kotsanas, \& Morgan, 2013).

\section{Optimise student-teacher ratios}

There is currently no 'gold standard' model of clinical education, that is, a 1:1 student-teacher ratio has no clear benefits over a 2:1 ratio (Lekkas et al., 2007). Using a 2:1 ratio may potentially reduce clinical educator time per learner through economies of scale and peer-peer learning.

\section{Match learning objects to period of use}

Developing an e-learning object is often expensive (Cook, 2014). This may be appropriate for anatomy content which can be used over a long period of time, however may not be the best option for content on the latest evidence for back pain management.

\section{Collaborate with other professions, institutions, and countries}

The National Simulation Project is a collaboration of 16 Australian Physiotherapy programmes through which 45 simulated patient scenarios were developed, implemented, and evaluated. These scenarios and information about the project is available on their website

(http://lamp.physio.curtin.edu.au/simproj/). Through sharing the cost of development, the per institution fixed cost is likely to be lower than if the institution developed the same learning resource independently.

\section{Facility costs}

Facility costs refers to the physical space required for the educational intervention (Levin et al., 2017). Factors to consider include seating capacity, technological requirements (e.g. projectors, computers), and room fittings (e.g. oxygen ports, ceiling hoist tracking). Other hidden costs include utilities, cleaning, room maintenance, and building depreciation.

From a facility cost perspective, educational design should maximise outside-classroom content. Blended learning pedagogies may achieve this goal by reducing face-to-face contact hours in favour of e-learning objects. Flipped classroom models may reduce facility costs through enabling shifts in class time allocation and the type of rooms (Chen, Lui, \& Martinelli, 2017), and has been shown to yield improved student learning compared to the traditional approach (Hew \& Lo, 2018). However, such approaches are highly heterogeneous (Liu et al., 2016), and depending on implementation, facility costs may not necessarily be different compared to traditional approaches (Maloney et al., 2015).

\section{Equipment and material costs}

In this section we will be discussing 'larger' equipment costs such as real-time ultrasound machines, standing hoists, simulation mannequins and rehabilitation gym equipment. It is acknowledged that 'smaller' material costs also exist, such as alcohol swabs, rigid tape, and office stationery - which may be relevant particularly in a low-budget setting.

Equipment costs can benefit from the economies of scope principle, which is the efficiency formed by variety. Often, physiotherapy programs use specialist equipment for only one or two weeks in the year, and then go back in storage until they are needed the following year. If a university teaches a variety of health professional courses, then the use (and cost) of the equipment can be shared accordingly. For example, it may be less costly to purchase a top-of-the-line simulation mannequin to be shared between a physiotherapy and nursing program, rather than each program buying a mid-tier mannequin that fits their individual needs. 
With equipment, it is also important to note that more expensive does not equal better education. For example, while high-fidelity simulators are typically much more expensive than their low-fidelity counterparts, evidence suggests that there is little difference in learning outcomes (Norman, Dore, \& Grierson, 2012), although formal cost analyses in simulation are lacking (Zendejas, Wang, Brydges, Hamstra, \& Cook, 2013). Overall, physiotherapy programs should carefully evaluate educational value and costs when looking to purchase equipment, and also consider alternatives such as lower-cost options or rentals.

\section{Client input costs}

All costs thus far have been discussed from the perspective of the educational institution. In physiotherapy education, costs may also be incurred by patients, governments, healthcare facilities, clinical educators, the broader community, and learners themselves (Haines, Isles, Jones, \& Jull, 2011). The allocation of costs between stakeholders is largely driven by the education system, and the degree to which education is private or publicly funded. In his editorial, Walsh (2015) highlights an increase in private medical schools, referring to India and Brazil as examples, suggesting that privatisation may improve overall efficiency, although we must be cautious that this does not occur at the expense of the educational mission. Related to privatisation is the issue of student debt, which is widely recognised as an ongoing issue for medical education (Steinbrook, 2008). The issue of debt has been explored to a lesser extent in the physiotherapy literature, with the most recent estimate of student debt from a Doctor of Physiotherapy degree in the United States put at US\$86,563 (Shields \& Dudley-Javoroski, 2018).

Designers of physiotherapy education should keep relevant stakeholder groups in mind (the client), as what initially appears to be a cost-saving, may actually be a cost-shifting to another stakeholder (Maloney et al., 2017). For example, in the evaluation of an interprofessional student clinic, compared to a conventional hospital-based placement, Haines et al. found a cost saving of AU $\$ 115$ from the government perspective, but an increase of AU\$289 to the university per student day (Haines, Kent, \& Keating, 2014).

Educators should consider the impact of their decisions on learner time, both in-class and out-of-class. In a study assessing the cost of a repeat physiotherapy clinical placement (after failure), the cost to students was found to be US\$4574 (for a five-week repeat), but would reduce to US\$856 if a one-week repeat structure was utilised - in which the largest contributor to cost was time (Foo et al., 2017). In addition to time, educational design can influence learner travel and accommodation costs.

\section{Conclusion}

In this editorial we have explored educational design concepts related to the cost of personnel, facilities, equipment, and client inputs. The examples provided are not an exhaustive list, rather, they have been provided to stimulate your interest and thought towards the role of economics in advancing physiotherapy education practices. Understanding principles of cost-conscious design, known as 'economic literacy', is a key skill for educators. Economic literacy not only promotes more efficient and sustainable education systems, but also supports educators in advocating for change through the ability to make economic arguments.

Evidence in this field is currently lacking. There is a need for organised, prospective research, grounded in educational and economic theory, and designed to compare multiple alternatives in terms of both costs and educational effects. Cost is just one element of the decision-making process, and should be considered together with factors such as educational value, equity, and inclusiveness in education.

We, the education community, have long avoided discussions of cost, perhaps in fear of sullying the sanctity of the scholastic mission. However, resource limitations are a reality, and we must learn to embrace a dialog about cost - or risk making ill-informed decisions.

\section{References}

Bithell, C. (2007). Entry-level physiotherapy education in the United Kingdom: governance and curriculum. Physical Therapy Reviews, 12(2), 145-155.

Brown, G. T., \& Jennifer, G. (1999). Occupational Therapy and Physiotherapy: Similar, but Separate. British Journal of Occupational Therapy, 62(4), 163-170. doi:10.1177/030802269906200406.

Chen, F., Lui, A. M., \& Martinelli, S. M. (2017). A systematic review of the effectiveness of flipped classrooms in medical education. Medical Education, 51(6), 585-597. doi:10.1111/medu.13272.

Cook, D. A. (2007). Web-based learning: pros, cons and controversies. Clinical Medicine, 7(1), 37-42. doi:10.7861/clinmedicine.7-1-37.

Cook, D. A. (2014). The value of online learning and MRI: Finding a niche for expensive technologies. Medical Teacher, 36(11), 965-972. doi:10.3109/0142159X.2014.917284.

Finucane, P., \& McCrorie, P. (2010). Chapter 2: Cost-effective undergraduate medical education. In K. Walsh (Ed.), Cost Effectiveness in Medical Education. Oxford: Radcliffe Publishing.

Foo, J., Rivers, G., Ilic, D., Evans, D. J. R., Walsh, K., Haines, T., ... Maloney, S. (2017). The economic cost of failure in clinical education: a multi-perspective analysis. Medical Education, 51(7), 740-754. doi:10.1111/medu.13266. 
Haines, T. P., Isles, R., Jones, A., \& Jull, G. (2011). Economic Consequences in Clinical Education. Focus on Health Professional Education: A Multi-disciplinary Journal, 12(3), $53-63$.

Haines, T. P., Kent, F., \& Keating, J. L. (2014). Interprofessional student clinics: an economic evaluation of collaborative clinical placement education. Journal of Interprofessional Care, 28(4), 292-298. doi:10.3109/13561820.2013.874983.

Harvey, L. A., Glinsky, J. V., Lowe, R., \& Lowe, T. (2014). A Massive Open Online Course for teaching physiotherapy students and physiotherapists about spinal cord injuries. Spinal Cord, 52, 911. doi:10.1038/sc.2014.174.

Hew, K. F., \& Lo, C. K. (2018). Flipped classroom improves student learning in health professions education: a meta-analysis. BMC Medical Education, 18, 38. doi:10.1186/s12909-018-1144-z.

Lekkas, P., Larsen, T., Kumar, S., Grimmer, K., Nyland, L., Chipchase, L., . . Finch, J. (2007). No model of clinical education for physiotherapy students is superior to another: a systematic review. Australian Journal of Physiotherapy, 53(1), 19-28. doi:10.1016/Sooo4-9514(07)70058-2.

Levin, H., McEwan, P., Belfield, C., Bowden, A., \& Shand, R. (2017). Economic Evaluation in Education: Cost-Effectiveness and Benefit-Cost Analysis (3 ed.). California: SAGE

Publications.

Liu, Q., Peng, W., Zhang, F., Hu, R., Li, Y., \& Yan, W. (2016). The effectiveness of blended learning in health professions: systematic review and meta-analysis. Journal of Medical Internet Research, 18(1). doi:10.2196/jmir.4807.

Maloney, S. (2017). When I say ... cost and value. Medical Education, 51(3), 246-247. doi:10.1111/medu.13139.

Maloney, S., Moss, A., Keating, J., Kotsanas, G., \& Morgan, P. (2013). Sharing teaching and learning resources: perceptions of a university's faculty members. Medical Education, $47(8)$, 811-819. doi:10.1111/medu.12225.

Maloney, S., Nicklen, P., Rivers, G., Foo, J., Ooi, Y. Y., Reeves, S., .. . Ilic, D. (2015). A Cost-Effectiveness Analysis of Blended Versus Face-to-Face Delivery of Evidence-Based Medicine to Medical Students. J Journal of Medical Internet Research, 17(7). doi:10.2196/jmir.4346.

Maloney, S., Reeves, S., Rivers, G., Ilic, D., Foo, J., \& Walsh, K. (2017). The Prato Statement on cost and value in professional and interprofessional education. Journal of Interprofessional Care, 31(1), 1-4. doi:10.1080/13561820.2016.1257255.

Maloney, S., Storr, M., Paynter, S., Morgan, P., \& Ilic, D. (2012). Investigating the efficacy of practical skill teaching: a pilot-study comparing three educational methods. Advances in Health
Sciences Education: Theory and Practice.

doi:10.1007/s10459-012-9355-2.

McEwan, P. J. (2012). Cost-effectiveness analysis of education and health interventions in developing countries. Journal of Development Effectiveness, 4(2), 189-213.

doi:10.1080/19439342.2011.649044.

McMeeken, J., Webb, G., Krause, K.-L., Grant, R., \& Garnett, R. (2005). Learning outcomes and curriculum development in Australian physiotherapy education. Melbourne: The University of Melbourne.

Norman, G., Dore, K., \& Grierson, L. (2012). The minimal relationship between simulation fidelity and transfer of learning. Medical Education, 46(7), 636-647. doi:10.1111/j.1365-2923.2012.04243.x.

Pretorius, A., Karunaratne, N., \& Fehring, S. (2015). Australian physiotherapy workforce at a glance: a narrative review. Australian Health Review, 40(4), 438-442. doi:10.1071/AH15114.

Shields, R. K., \& Dudley-Javoroski, S. (2018). Physiotherapy education is a good financial investment, up to a certain level of student debt: an inter-professional economic analysis. Journal of Physiotherapy.

doi:https://doi.org/10.1016/j.jphys.2018.05.009.

Steinbrook, R. (2008). Medical student debt-is there a limit? New England Journal of Medicine, 359(25), 2629-2632.

Walsh, K. (2010). Cost Effectiveness in Medical Education: Radcliffe Publishing.

Walsh, K. (2015). Medical schools for profit? Annals of Medical and Health Sciences Research, 5(3), 155-156.

doi:10.4103/2141-9248.157475.

World Confederation for Physical Therapy. (2015a). Physical therapy: a global profile. Retrieved from

http://www.wcpt.org/news/Infographics-profile-profession-Ma y15.

World Confederation for Physical Therapy. (2015b). Policy statement: Education. Retrieved from http://www.wcpt.org/policy/ps-education.

Zendejas, B., Wang, A. T., Brydges, R., Hamstra, S. J., \& Cook, D. A. (2013). Cost: the missing outcome in simulation-based medical education research: a systematic review. Surgery, 153(2), 160-176. doi:10.1016/j.surg.2012.06.025. 


\section{Peer review reports}

Benjamin Ellis (B.Ellis@bham.ac.uk)

Reviewed: 15 June 2018

Citation: Ellis, B. (2018). Review - What do students learn about communication: The influence of the physiotherapy curriculum in constructing understandings of communication. DOI:

10.14426/opj/20180615

Nina Rydland Olsen (Nina.Rydland.Olsen@hvl.no)

Reviewed: 7 May 2018

Citation: Olsen, R. (2018). Review - What do students learn

about communication: The influence of the physiotherapy

curriculum in constructing understandings of communication.

DOI: $10.14426 /$ opj/20180507 